\title{
Limestone and siliceous aggregate concretes subjected to sulphuric acid attack*
}

\author{
B. P. Hughes and J. E. Guest \\ Contribution by Adam Neville \\ University of Leeds $\dagger$
}

The paper is useful in that it reminds readers of earlier information on the behaviour of calcareous aggregates under acid attack. For instance, as far back as 1960, van Aardt" ${ }^{(1)}$ wrote "The useful life of concrete sewer pipes can be very considerably lengthened, probably at least doubled, by using calcareous aggregate such as a suitable limestone or dolomite instead of a siliceous one in the concrete." Even in the first edition of Properties of concrete published in 1963 there is a statement to the effect that attack by pure water or water containing $\mathrm{CO}_{2}$ "may be of importance in conduits in mountain regions, not only from the standpoint of durability but also because the leaching out of cement leaves behind protruding aggregate and thus increases the roughness of the pipe. For this reason the use of calcareous rather than siliceous aggregate is advantageous". ${ }^{(2)}$ It is nice to know that the validity of these statements is confirmed.

\section{Reply by the authors}

We thank Professor Neville for his contribution and his references supporting the main conclusion of the paper: namely, that the use of a calcareous aggregate, which is no more susceptible to attack than the cementitious matrix under the particular conditions of exposure, can be very desirable and should be

encouraged rather than discouraged. It is hoped that the paper has helped to replace limestone aggregate in its correct perspective - that good hard limestone aggregates can be even better than siliceous aggregates for use in concrete and that only poor limestones should be avoided.

\section{REFERENCES}

1. VAN AARDT, J. H. P. Chemical and physical aspects of weathering and corrosion of cement products with special reference to the influence of warm climate. RILEM International symposium on concrete and reinforced concrete in hot countries, Haifa, 1960. Haifa, Building Research Station, 1960. pp. 14.

\footnotetext{
*Pages 11 to 18 of $M C R 102$.

$\dagger$ Professor Neville is now Principal and Vice-Chancellor, University of Dindee.
}

2. Neville, A. M. Properties of concrete. London, Pitman Publishing Co. First edition 1963, Second edition 1973. pp. 687. 